\title{
Heat Capacity and Thermal Expansion at Low Temperatures
}

\section{T. H. K. Barron}

University of Bristol

Bristol, United Kingdom

\section{and}

\section{G. K. White}

CSIRO

Lindfield, Australia

Kluwer Academic/Plenum Publishers New York, Boston, Dordrecht, London, Moscow 


\section{Contents}

Chapter 1. Introduction $\ldots \ldots \ldots \ldots \ldots \ldots \ldots \ldots$

1.1. Thermodynamic Properties at Low Temperatures . . . 1

1.2. Implications for Design of Equipment $\ldots \ldots \ldots \ldots 11$

1.3. Useful Theoretical Concepts . . . . . . . . . 13

1.4. Plan of This Book . . . . . . . . . . . 24

Chapter 2. Basic Theory and Techniques $\ldots \ldots \ldots \ldots \ldots \ldots$

2.1. Introduction . . . . . . . . . . . 27

2.2. Thermodynamics . . . . . . . . . . 27

2.3. Statistical Mechanics . . . . . . . . . . 37

2.4. Bonding and Interatomic Potentials . . . . . . . 45

2.5. Some Model Systems . . . . . . . . . . . . . 48

2.6. Lattice Vibrations . . . . . . . . . . . . 54

2.7. Approximate Equations of State . . . . . . . 73

2.8. Anisotropic Strain and Stress: Elasticity . . . . . . 76

2.9. Calculation of $\Theta_{0}^{e l}, \gamma_{0}^{e l}$ and $\gamma_{\lambda, 0}^{e l}$ from Elastic Data . . . 86

2.10. Internal Strain . . . . . . . . . . . 88

Chapter 3. Measurement Techniques . . . . . . . . . 89

3.1. General Principles . . . . . . . . . . . . . . . . 89

3.2. Heat Capacity ... by S. J. Collocott . . . . . . 93

3.3. Thermal Expansion . . . . . . . . . . . 105

3.4. Elastic Moduli . . . . . . . . . . . . . 118 
Chapter 4. Fluids . . . . . . . . . . . . . . . . 129

4.1. Introduction . . . . . . . . . . . . . 129

4.2. Gases . . . . . . . . . . . . . . . 130

4.3. Liquids and Dense Gases . . . . . . . . . . . . 137

4.4. Quantum Fluids; Liquid Helium . . . . . . . . . 141

Chapter 5. Non-Metals . . . . . . . . . . . . 153

5.1. Introduction . . . . . . . . . . . 153

5.2. Rare Gas Solids . . . . . . . . . . . . . . . 154

5.3. Rocksalt Structure . . . . . . . . . . . . . . 157

5.4. Fluorite Structure . . . . . . . . . . . . . 161

5.5. Tetrahedrally Bonded Crystals . . . . . . . . . . 162

5.6. Useful Oxides: $\alpha-\mathrm{Al}_{2} \mathrm{O}_{3}, \mathrm{MgO}, \alpha-\mathrm{SiO}_{2}, \mathrm{TiO}_{2}, \mathrm{ThO}_{2}$,

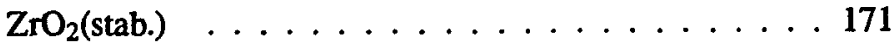

5.7. Glasses and Glass Ceramics . . . . . . . . . . 174

5.8. Highly Anisotropic Crystals . . . . . . . . . 188

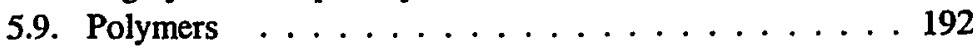

5.10. High $T_{c}$ Superconductors $\ldots \ldots \ldots$. . . . . . 200

5.11. Non-Metallic Magnetic Crystals . . . . . . . . . 210

5.12. Mixed Systems, Dipoles etc. . . . . . . . . . 217

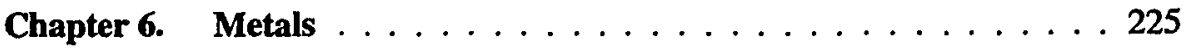

6.1. Introduction . . . . . . . . . . 225

6.2. Cubic Metals . . . . . . . . . . . . . 228

6.3. Non-Cubic Metals . . . . . . . . . . . . . . . . . 239

6.4. Magnetic Metals . . . . . . . . . . . 246

6.5. Type I and Type II Superconductors . . . . . . . . . 254

6.6. Heavy Electron Metals . . . . . . . . . . . . . . 262

Chapter 7. Polycrystals, Composites and Aggregates $\ldots \ldots \ldots 267$

7.1. Introduction . . . . . . . . . . . . 267

7.2. Theory . . . . . . . . . . . . . . . . . 269

7.3. Experiment $\ldots \ldots \ldots \ldots . \ldots \ldots 274$

Chapter 8. Cryocrystals, Clathrates and Curiosities . . . . . . . . 277

8.1. Cryocrystals . . . . . . . . . . . . . . . . . . 277

8.2. Other Rotationally Disordered Crystals . . . . . . . 281

8.3. Clathrates . . . . . . . . . . . . . . . 284

8.4. Curiosities . . . . . . . . . . . . . . . . 287 
Chapter 9. Conclusion . . . . . . . . . . . . . . . 295

Appendix A. Axes and Unit Cells in Crystals . . . . . . . . . . . . 297

Appendix B. Manipulating Thermodynamic Expressions _ . . . . . 299

Appendix C. Tables $\ldots \ldots \ldots \ldots \ldots \ldots \ldots \ldots \ldots \ldots \ldots$

Appendix D. Commonly Used Symbols . . . . . . . . . . . 311

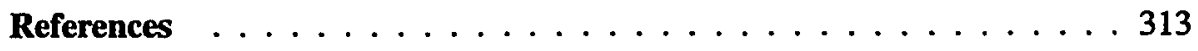

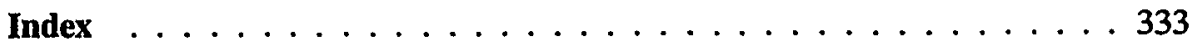

